\title{
Not just another thunderclap headache: a case of isolated cortical vein thrombosis and subarachnoid haemorrhage
}

\author{
Edith Vassallo, Christine Azzopardi, Reuben Grech
}

Mater Dei Hospital, Msida Malta

Correspondence to Dr Christine Azzopardi, chrissyazz@yahoo.com

Accepted 26 October 2015

\section{DESCRIPTION}

A 63-year-old woman presented with a severe frontal thunderclap headache associated with transient blurring of vision. No significant medical history other than blood hypertension was noted. On examination, there was no neck stiffness or fever, however, her blood pressure was 160/ $90 \mathrm{~mm} \mathrm{Hg}$. Ophthalmoscopic assessment excluded papilloedema and neurological examination was unremarkable.

A non-contrast CT scan showed a small subarachnoid haemorrhage $(\mathrm{SAH})$ in the frontal region bilaterally (figure 1A). A cerebral CT angiogram failed to reveal any aneurysms. She proceeded to have an MRI. The fluid-attenuated inversion recovery sequence confirmed the subarachnoid bleed (figure 1B), while the time of flight MR angiography was normal (figure $1 \mathrm{C}$ ). An MR venogram ruled out thrombosis of the major venous sinuses (figure 2A), while the T1-weighted images confirmed thrombosis of the frontal cortical veins (figure 2B, C). The patient was started on heparin and the headaches gradually improved.

Cortical vein thrombosis (CVT) accounts for $1-2 \%$ of strokes in young adults. ${ }^{1}$ Isolated CVT without venous sinus involvement is rare, occurring in $6 \%$ of cerebral venous thrombosis, ${ }^{2}$ though this finding may be overlooked. The underlying mechanism remains unclear. Neurological deficits following seizures, including hemiparesis, aphasia and hemianopia, without evidence of raised intracranial pressure, should raise the possibility of this condition. Presentation of CVT with SAH is extremely rare, with few cases reported in the literature.

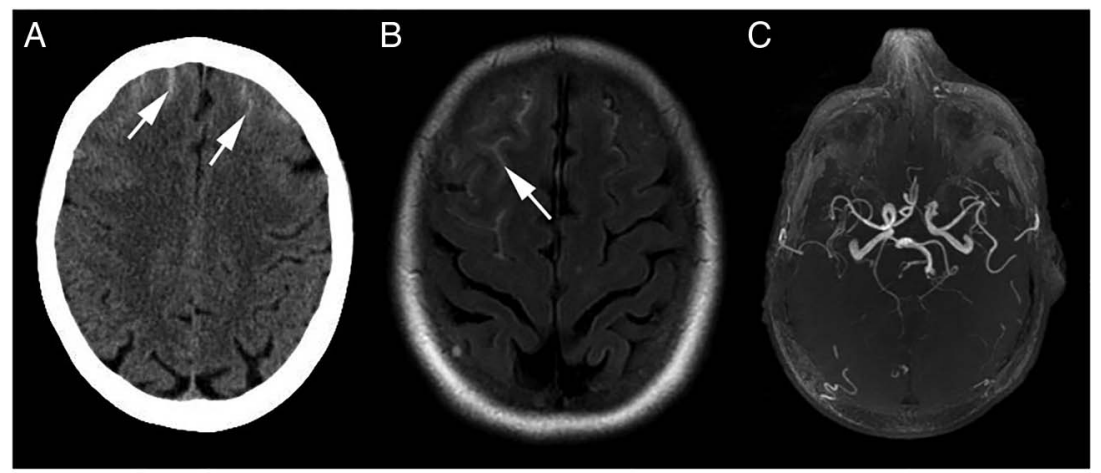

Figure 1 Unenhanced axial CT of the brain (A) showing high attenuation filling the superior frontal sulci bilaterally (arrows, A) consistent with subarachnoid haemorrhage. Axial fluid-attenuated inversion recovery sequence (B) exquisitely depicts the extension of the subarachnoid haemorrhage (arrow, B), which is more prominent on the right. Time-of-flight MR angiography (C) demonstrating a normal circle of Willis with no evidence of Berry aneurysms.

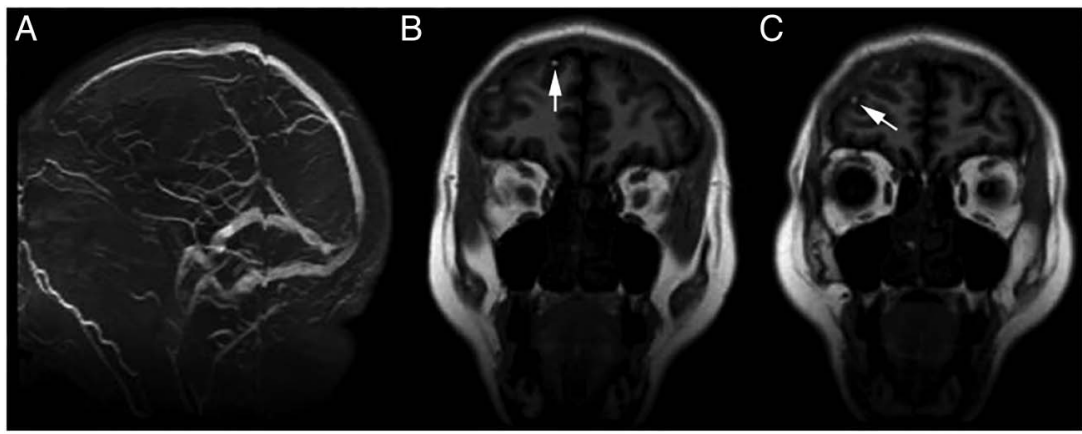

Figure 2 MR venogram (A) demonstrating normal cerebral venous sinuses with no evidence of thrombosis. Coronal fluid-attenuated inversion recovery (FLAIR) sequence (B) showing intraluminal high signal intensity in one of the right cortical cerebral veins (arrow, B). Coronal FLAIR sequence (C) demonstrating similar findings in a more laterally sited cortical vein representing thrombus within it consistent with cortical vein thrombosis. 
The MR appearance of a thrombosed cortical vein depends on the age of the clot and appears hyperintense on T1-weighted and T2-weighted sequences, which corresponds to the methaemoglobin state. ${ }^{3}$ Conventional angiography may confirm the diagnosis.

\section{Learning points}

- Cortical vein thrombosis accounts for $1-2 \%$ of strokes in young adults and the diagnosis is made on MRI.

- Isolated cortical vein thrombosis without sinus involvement is rare.

- Presentation of cortical vein thrombosis with subarachnoid haemorrhage is extremely rare.
Acknowledgements The authors would like to thank the neurologists involved in the treatment of this patient.

Contributors RG was responsible for planning of the manuscript; EV and CA for the preparation; and RG for supervision.

Competing interests None declared.

Patient consent Obtained.

Provenance and peer review Not commissioned; externally peer reviewed.

\section{REFERENCES}

1 Changa R, Fiedmana DP. Isolated cortical venous thrombosis presenting as subarachnoid hemorrhage: a report of three cases. AJNR Am J Neuroradiol 2004;25:1676-9.

2 Cohen JE, Duck M, Gomori JM, et al. Isolated cortical vein thrombosis: a rare cause of venous stroke with a good prognosis after timely diagnosis and treatment. Neurol Res 2013:35:127-30.

3 Connor SE, Jarosz JM. Magnetic resonance imaging of cerebral venous sinus thrombosis. Clin Radiol 2002;57:449-61.

Copyright 2015 BMJ Publishing Group. All rights reserved. For permission to reuse any of this content visit

http://group.bmj.com/group/rights-licensing/permissions.

BMJ Case Report Fellows may re-use this article for personal use and teaching without any further permission.

Become a Fellow of BMJ Case Reports today and you can:

- Submit as many cases as you like

- Enjoy fast sympathetic peer review and rapid publication of accepted articles

- Access all the published articles

- Re-use any of the published material for personal use and teaching without further permission

For information on Institutional Fellowships contact consortiasales@bmjgroup.com

Visit casereports.bmj.com for more articles like this and to become a Fellow 